\title{
'Mikado' ve 'Mogador' kayısı çeşitlerinde Bud Feed uygulamasının meyve tutumu, verim ve meyve kalitesine etkileri
}

Effects of Bud Feed application on fruit set, yield and fruit quality in 'Mikado' and 'Mogador' apricot cultivars

\author{
Oğuzhan ÇALIŞKAN ${ }^{1 \mathcal{P}}$ (D) , Derya KILIÇ ${ }^{1}$ iD, Safder BAYAZIT ${ }^{1}$ (D) \\ ${ }^{1}$ Hatay Mustafa Kemal University, Faculty of Agriculture, Department of Horticulture, Antakya-Hatay, Turkey.
}

MAKALE BILGISI / ARTICLE INFO

\section{Makale tarihçesi / Article history:}

DOI: $10.37908 /$ mkutbd.907725

Geliş tarihi /Received:01.04.2021

Kabul tarihi/Accepted:14.05.2021

\section{Keywords:}

Apricot, bud feed, chilling duration, yield, quality.

Corresponding author: Oğuzhan
ÇALIŞKAN
$\square: \underline{\text { ocaliskan@mku.edu.tr }}$

\author{
ÖZET / A B STRACT
}
Atıf / Citation: Çalışkan O, Kılıç D, Bayazıt S (2021) 'Mikado' ve 'Mogador' kayısı çeşitlerinde Bud Feed uygulamasının meyve tutumu, verim ve meyve kalitesine etkileri. MKU. Tar. Bil. Derg. 26(2) : 345-354. DOI: 10.37908/mkutbd.907725

\section{GiRiş}

Türkiye'nin Akdeniz Bölgesi, ekolojinin sağladığı erkencilik nedeniyle turfanda meyve yetiştiriciliğine oldukça elverişli alanlara sahiptir. Bu bölgede yapılan meyvecilik çalışmalarında, hem ülkemizdeki öteki bölgelerden hem de Avrupa'nın önemli meyvecilik ülkeleri olan İspanya, İtalya ve Fransa'dan 10-15 gün daha erkencilik sağladığı belirtilmektedir (İmrak ve ark., 2009; Çalışkan ve ark., 2012). Kaşka ve ark. (1981), Akdeniz Bölgesinin diğer güney Avrupa ülkelerine göre erkenci olmasında bulunduğu enlemin 36 . ve 37 . derecelerde olmasından kaynaklandığını ve enlem derecesindeki her bir birim azalmanın 4-5 gün erkencilik sağladığını bildirmişlerdir. Bu bakımdan, Akdeniz Bölgesi soğuklaması düşük kayısı, şeftali-nektarin, kiraz ve erik gibi sert çekirdekli meyve türlerinde erkenci yetiştiricilik ile ön plana çıkmaktadır. Bu türlerde çeşitlerin oldukça dinamik bir yapıya sahip olması nedeniyle, yeni çeşitlerin adaptasyonunun yapılması ve sonrasında yetiştiriciliğinin yaygınlaşması gerektiği Kaşka (2001) tarafından ifade edilmiştir.

Akdeniz Bölgesi, 293.336 ton taze kayısı üretimi ile 833.389 ton olan Türkiye kayısı üretiminin \%29'nu karşılamaktadır. Bölgenin önemli kayısı yetiştiricilik merkezleri Mersin (170.468 ton), Kahramanmaraş 
(65.477 ton) ve Hatay (35.941 ton) illeridir (Anonim, 2021a). Bölgede yetiştirilen kayısı çeşitleri çoğunlukla erkenci ('Mikado' ve 'Mogador') ve orta-erkenci ('Bebeco', 'Çağataybey', 'Alyanak') grupta yer alan çeşitlerden oluşmaktadır. Yetiştirilen erkenci çeşitlerin meyveleri genellikle ihracata konu olmaktadır. 2020 yılı Türkiye yaş meyve-sebze ihracatçı birliklerinin verilerine göre (Anonim, 2021b), Mayıs ayında 21.7 bin ton kayısı (15.7 milyon dolar) ihracatının tamamı Akdeniz Bölgesinden gerçekleştirilmiş ve bu dönemde erkenci kayısı ihracatında kg fiyatının 1 Amerikan dolarına yakın gerçekleşmesi ile üreticisine önemli kar sağlamıştır.

Meyve yetiştiriciliğinde bölgelere çeşit tavsiyesi yapılırken dikkat edilmesi gereken önemli hususlardan birisi çeşitlerin soğuklama gereksinimleridir. Çoğu bitki türünün ilkbaharda dinlenmeden çıkıp, sağlıklı büyüme ve gelişmesini sürdürmesi için belirli bir kış soğuğuna ve sonrasında ilkbaharda hava sıcaklıklarına gereksinim duyarlar. Bitkilerin soğuklama ve sıcaklık istekleri genetik yapı tarafından kontrol edilmekte ve çeşide bağı ılarak değişkenlik göstermekle birlikte (Castède ve ark., 2014) soğuklama süresi için etkili olan sıcaklıklar 0 ile $7.2^{\circ} \mathrm{C}$ arası kabul edilmektedir (Weinberger, 1950).

Kışın havaların sıcak veya Ilık geçmesi durumunda kayısı gibi sert çekirdekli meyve türleri soğuklama sürelerini yeteri kadar karşılayamazlar. Bu durumda çiçek tomurcuklarında dökülme, düzensiz çiçeklenme ve yapraklanma, dallarda boşluklar oluşması, yetersiz meyve tutumu, çeşidin kendine ait meyve kalite özelliklerini göstermemesi ve düşük verim gibi ciddi kayıplara neden olabilmektedir (Erez, 2000; Viti ve ark., 2008). Küresel ısınmanın bir sonucu olarak kış soğuklarında meydana gelen azalmalar soğuklama gereksiniminin karşılanmasındaki problemlerin artarak devam edeceğini göstermektedir (Campoy ve ark., 2011). Bu nedenle, Akdeniz Bölgesi gibi erkenci yetiştiricilik alanlarında çeşit önerisinde bulunurken soğuklama isteği düşük çeşitlere yönelinmesi en önemli hususların başında gelmektedir. Bununla birlikte, bu çeşitlerde soğuklama süresinin yetersiz kalması durumunda bitkinin dinlenmeden çıkmasını sağlayıcı uygulamalar (DNOC, mineral yağlar, hidrojen siyanamid, gibberellinler, $\mathrm{KNO} 3$, thioure gibi) ile yeterli meyve tutumu ve ekonomik verimin elde edilebilmektedir (Cook ve ark., 2001; Engin ve ark., 2004; Son ve Küden, 2005; Zhuang ve ark., 2015; İmrak ve ark., 2016). Bu amaçla, sert çekirdekli meyvelerde yaygın olarak kullanılan hidrojen siyanamid kullanımı ülkemizde 2010 yılında yasaklanmıştır. Bu nedenle, son yıllarda azot içeren (özellikle düşük biüretli üre) bileşenlerin bitkilerin dinlenmeden çıkışında etkisi konusunda araştırmalar bulunmaktadır. İmrak ve ark. (2016), toplam \%15 azot içeren uygulamanın Adana ekolojisinde yetiştirilen Modi ${ }^{\mathrm{TM}}$ elma çeşidinde kontrolde $5.3 \mathrm{~kg}$ olan ağaç başına meyve veriminin uygulamada $7.5 \mathrm{~kg}$ ağaç ${ }^{-1}$ olduğunu bildirmişlerdir.

Akdeniz Bölgesinde yer alan Hatay ili, sahip olduğu erkenci ekoloji ile turfanda meyve yetiştiriciliği için oldukça uygun alanlara sahiptir. 2020 yılı verilerine göre Hatay ilinde 35.941 ton kayısı üretimi gerçekleşmiş olup, 71.000'nin üzerinde meyve vermeyen ağaç varlığı ile yakın zamanda bu üretimin daha da artacağı öngörülmektedir (Anonim, 2021a). Yelmen (2007), Hatay ili Antakya merkez ilçenin soğuklama süresini uzun yıllar meteorolojik verileri kullanarak (1963-2003 yılları) hesaplamış ve bu sürenin klasik yöntemde 799 saat olduğu bildirilmiş ve soğuklama süresinin gelecek yıllarda yıllık 400-600 saat arasında değişim göstereceği tahmin edilmiştir. Bununla birlikte, bu alanda 2010-2020 yılları arasında meydana gelen soğuklama süresinin 237 saate kadar düştüğü (Anonim, 2021c) ve bu kapsamda soğuklamanın yetersiz olması durumunda kullanılacak pratik uygulamalara gereksinim duyulmaktadır. Son yıllarda, Doğu Akdeniz Bölgesinde erkenci kayısı çeşitlerinden 'Mikado' ve 'Mogador' çeşitlerinin yaygınlaştığı görülmektedir. 'Mogador' kayısı çeşidinin erkenci olmakla birlikte özellikle yeme kalitesinin yüksek olması ile tüketiciler tarafından beğenildiği (Melgarejo ve ark., 2013) ve 'Mikado' çeşidinin ise oldukça erkenci olması ile ön plana çıktığı (Melgarejo ve ark., 2021) belirtilmektedir.

Bu çalışmanın amacı, erkenci 'Mikado' ve 'Mogador' kayısı çeşitlerinde Bud Feed uygulamasının meyve tutumu, verim ve meyve kalitesine olan etkilerini belirlemektir.

\section{MATERYAL ve YÖNTEM}

Bu çalışma, Hatay Mustafa Kemal Üniversitesi Ziraat Fakültesi Bahçe Bitkileri Bölümüne ait araştırma ve uygulama alanında 2019-2020 gelişme periyodunda gerçekleştirilmiştir. Çalışmada, 2017 yılı Mayıs ayında 2.5x3 m olarak dikilen Myrobolan 29-C erik anacı üzerine aşılı 'Mikado' (Patent No: 'Mikado' COV CEE No 2014/2511) ve 'Mogador' (Patent No: Mogador COV CEE $N^{\circ}$ 2007/0091) kayısı çeşitleri (PSB Produccí on Vegetal $S L$, Murcia, İspanya) kullanılmıştır.

Araştırma alanın gübreleme, hastalık ve zararlılarla mücadelesi gibi teknik ve kültürel işlemler standart olarak uygulanmıştır. Çalışma yapılan alanın toprak $\mathrm{pH}^{\prime} \mathrm{sı}$ 7.81 olup, toprak yapısı \%39.5 kum, \%25.3 kil ve \%6.10 kireç içeriği ile kumlu-killi bir yapıya sahiptir. Toprağın toplam tuz içeriği \%0.035-0.041 değerleri ile tuzsuz sınıfa girmektedir. 
Çalışma kapsamında \%15 oranında düşük biüretli üre içeren Bud Feed (Stoller Türkiye, İzmir) uygulaması üç tekerrürlü ve her tekerrürde bir bitki olacak şekilde tomurcuk patlamasında 35 gün önce (10 Ocak) $6 \mathrm{~L} 100 \mathrm{~L}^{-}$ ${ }^{1}$ olarak uygulanmıştır. Aynı dönemde kontrol ağaçlarına sadece su püskürtülmüştür. Tomurcukların $\% 50$ 'sinin patladığı dönem dinlenmeden çıkış tarihi olarak belirlenmiştir (Küden ve Kaşka, 1992).

Sıcaklık gereksinimleri, büyüme sıcaklık dereceleri toplamı olarak incelenmiş olup, $4.5^{\circ} \mathrm{C}$ 'nin üzerindeki sıcaklıklar dikkate alınmıştır (Richardson ve ark., 1975). $\mathrm{Bu}$ değerlendirmede $25^{\circ} \mathrm{C}$ 'nin üzerindeki sıcaklıklar dikkate alınmamıştır. Büyüme derece sıcaklık toplamları BDST1 (tam çiçeklenmeden 30 gün sonrasına kadar) ve BDST2 (tam çiçeklenmeden hasada kadar) olarak değerlendirilmiştir.

Çalışma kapsamında fenolojik gözlemlerden tomurcuk patlaması, ilk çiçeklenme (\%5 çiçeklenme), tam çiçeklenme (\%70 çiçeklenme) ve çiçeklenme sonu (\%90 taç yaprak dökümü) gözlemleri yapılmıştır. Çeşitlerin meyve hasadı ticari olum döneminde ve çeşide özgü irilik ve rengin oluştuğunda gerçekleştirilmiştir (Ayanoğlu ve Kaşka, 1995).

Çiçek açma oranı (\%), ilk meyve tutma oranı (\%) ve hasattaki meyve tutma oranı (\%) değerleri Westwood (1995)'e göre değerlendirilmiştir.

Meyve kalite analizleri üç yinelemeli ve her yinelemede 10'ar meyve olacak şekilde toplam 30 meyve üzerinde sürdürülmüştür. Bu kapsamda meyve ağırlığı (g), meyve boyutları (eni, boyu ve yüksekliği; mm), çekirdek ağırlığı (g), et/çekirdek oranı, suda çözünebilir toplam kuru madde miktarı (SÇKM), $\mathrm{pH}$ ve titre edilebilir asit (\%) ölçümleri yapılmıştır. Meyve kabuk ve et rengi ölçümleri renk ölçer (CR-300, Minolta) ile gerçekleştirilmiştir. Renk okumaları L, a*, b*, C (Chroma) ve $h^{\circ}$ (hue) açı değeri olarak değerlendirilmiştir. Meyve kabuk ölçümleri her meyve karşılıklı iki yanakta gerçekleştirilirken, meyve et rengi ölçümleri meyvenin boyuna kesilmesi sonrasında her iki parçada birer kez gerçekleştirilmiştir (Çalışkan ve ark., 2012). Ayrıca, verim özelliklerinden ağaç başına verim ( $\left.\mathrm{kg} \mathrm{ağaç}^{-1}\right)$, gövde kesit alanına düşen verim $\left(\mathrm{kg} \mathrm{cm}^{-}\right.$ ${ }^{2}$ ) ve dekara verim (ton $\mathrm{da}^{-1}$ ) incelenmiştir.

\section{Deneme deseni ve istatistik analiz}

Çalışmada yer alan Bud Feed uygulamasının çeşitlerin meyve tutumu, verim ve meyve kalite özelliklerine ait ortalamaları SAS paket programında (SAS, 2005) T-testi ile karşılaştırılmıştır.

\section{BULGULAR ve TARTIŞMA}

\section{Araştırmada fenolojik gözlemler ve soğuklama süresi}

Bud Feed uygulamasının 'Mikado' ve 'Mogador' kayısı çeşitlerinin fenolojik aşamalarına etkileri Çizelge 1'de verilmiştir. Buna göre, 'Mikado' çeşidinde Bud Feed uygulaması kontrol bitkilerine göre tomurcuk patlaması, pembe tomurcuk ve ilk çiçeklenme dönemlerinde 2 günlük (sırasıyla, 08 Şubat, 17 Şubat ve 22 Şubat), tam çiçeklenme döneminde 3 günlük (01 Mart) ve hasatta 2 günlük (04 Mayıs) erkencilik sağlamıştır. 'Mikado' çeşidinde tomurcuk patlamasına kadar geçen sürede kontrol bitkilerinde 337 saat ve 518 SB soğuklama süresi meydana gelirken, Bud Feed uygulanan bitkilerde 326 saat ve 470 SB soğuklama süresi meydana gelmiştir (Çizelge 2).

Çizelge 1. 'Mikado' ve 'Mogador' çeşitlerinde Bud Feed uygulamasının bazı fenolojik özelliklere etkisi

Table 1. Effect of Bud Feed application on some phenological properties of 'Mikado' and 'Mogador' cultivars

\begin{tabular}{|c|c|c|c|c|c|c|c|}
\hline Çeşitler & Uygulama & $\begin{array}{l}\text { Tomur. } \\
\text { Patlaması }\end{array}$ & $\begin{array}{l}\text { Pembe } \\
\text { Çiçek }\end{array}$ & $\begin{array}{c}\text { ilk } \\
\text { Çiçek. }\end{array}$ & $\begin{array}{l}\text { Tam } \\
\text { Çiçek. }\end{array}$ & $\begin{array}{l}\text { Çiçeklenme } \\
\text { Sonu }\end{array}$ & $\begin{array}{l}\text { Hasat } \\
\text { Tarihi }\end{array}$ \\
\hline \multirow{2}{*}{ Mikado } & Kontrol & 10 Şubat & 19 Şubat & 26 Şubat & 04 Mart & 08 Mart & 06 Mayıs \\
\hline & Bud Feed & 08 Şubat & 17 Şubat & 22 Şubat & 01 Mart & 06 Mart & 04 Mayıs \\
\hline \multirow{2}{*}{ Mogador } & Kontrol & 22 Şubat & 29 Şubat & 03 Mart & 07 Mart & 13 Mart & 06 Mayıs \\
\hline & Bud Feed & 19 Şubat & 26 Şubat & 29 Şubat & 05 Mart & 10 Mart & 04 Mayıs \\
\hline
\end{tabular}

Mogador çeşidinde Bud Feed uygulamasının tomurcuk patlaması ile oluşan çiçeklenme fenolojisinde 3 günlük (tam çiçeklenme hariç) ve hasatta ise 2 günlük (04 Mayıs) erkencilik oluşturmuştur (Çizelge 1). Mogador çeşidinde tomurcuk patlamasına kadar geçen sürede kontrol bitkilerinde 362 saat ve 565 SB soğuklama süresi gerçekleşirken, Bud Feed uygulanan bitkilerde 349 saat ve 542 SB soğuklama süresi gerçekleşmiştir (Çizelge 2).Petri ve ark. (2010), Imperial Gala ve Supremas's Fuji elma çeşitlerinde \%15 azot $+\% 5$ kalsiyum nitrat uygulamasının, uygulama zamanına göre tomurcuk patlamasına kadar geçen sürede hesaplanan soğuklama süresi 400 saatten 274 saate kadar düştüğünü ve tam çiçeklenmenin kontrole göre en az 1-3 gün arasında değişen erkencilik sağladığını bildirmişlerdir. Demiral ve Ülger (2019), örtüaltında saksıda yetiştirilen Aurora, Ninfa ve Roxana kayısı çeşitlerinde dinlenmeyi kesmek amaciyla uygulanan \%2.5 dormex ve 200 ppm GA3 
uygulamalarının kontrol bitkilerine göre 2-7 günlük erkencilik sağladığını belirtmişlerdir.

Çizelge 2. 'Mikado' ve 'Mogador' çeşitlerinde Bud Feed uygulamasının tomurcuk patlama dönemine kadar meydana gelen soğuklama sürelerine etkisi (2019-2020 yılı)

Table 2. Effect of Bud Feed application on chilling durations of 'Mikado' and 'Mogador' cultivars until bud break (20192020 year)

\begin{tabular}{|c|c|c|c|c|c|c|c|c|}
\hline \multirow{3}{*}{ Aylar } & \multicolumn{4}{|c|}{ Mikado } & \multicolumn{4}{|c|}{ Mogador } \\
\hline & \multicolumn{2}{|c|}{ Kontrol } & \multicolumn{2}{|c|}{ Bud Feed } & \multicolumn{2}{|c|}{ Kontrol } & \multicolumn{2}{|c|}{ Bud Feed } \\
\hline & $\begin{array}{l}\text { Standart } \\
\text { Yöntem }\end{array}$ & $\begin{array}{c}\text { Soğuk } \\
\text { Birim }\end{array}$ & $\begin{array}{l}\text { Standart } \\
\text { Yöntem }\end{array}$ & $\begin{array}{c}\text { Soğuk } \\
\text { Birim }\end{array}$ & $\begin{array}{l}\text { Standart } \\
\text { Yöntem }\end{array}$ & $\begin{array}{c}\text { Soğuk } \\
\text { Birim }\end{array}$ & $\begin{array}{l}\text { Standart } \\
\text { Yöntem }\end{array}$ & $\begin{array}{c}\text { Soğuk } \\
\text { Birim }\end{array}$ \\
\hline Aralık & 102 & 121 & 102 & 121 & 102 & 121 & 102 & 121 \\
\hline Ocak & 170 & 236 & 170 & 236 & 170 & 236 & 170 & 236 \\
\hline Şubat & 65 & 161 & 54 & 113 & 90 & 208 & 77 & 185 \\
\hline Toplam & 337 & 518 & 326 & 470 & 362 & 565 & 349 & 542 \\
\hline
\end{tabular}

Çizelge 3. 'Mikado' ve 'Mogador' çeşitlerinde Bud Feed uygulamasının büyüme derece sıcaklık toplamlarına etkisi Table 3. Effect of Bud Feed application on growing degree hours of 'Mikado' and 'Mogador' cultivars

\begin{tabular}{lcccccccc}
\hline & \multicolumn{4}{c}{ Mikado } & \multicolumn{4}{c}{ Mogador } \\
\cline { 2 - 9 } Aylar & \multicolumn{2}{c}{ Büyüme Derece Sıcaklık Toplamı (BDST) } & \multicolumn{2}{c}{ Büyüme Derece Sıcaklık Toplamı (BDST) } \\
\cline { 2 - 9 } & \multicolumn{2}{c}{ Kontrol } & \multicolumn{2}{c}{ Bud Feed } & \multicolumn{2}{c}{ Kontrol } & Bud Feed \\
\cline { 2 - 10 } & \multirow{2}{*}{ BDST1 } & \multirow{2}{*}{ BDST2 } & BDST1 & \multirow{2}{*}{ BDST2 } & \multirow{2}{*}{ BDST1 } & \multirow{2}{*}{ BDST2 } & \multirow{2}{*}{ BDST1 } & BDST2 \\
\hline Mart & 6.635 & 6.635 & 7.340 & 7.340 & 5.827 & 5.827 & 6.385 & 6.385 \\
Nisan & 1.038 & 7.592 & 0 & 7.592 & 1.974 & 7.592 & 1.348 & 7.592 \\
Mayıs & 0 & 1.655 & 0 & 1.176 & 0 & 1.655 & 0 & 1.176 \\
Toplam & 7.673 & 15.882 & 7.340 & 16.108 & 7.801 & 15.074 & 7.733 & 15.153 \\
\hline
\end{tabular}

Bu çalışmada yer alan 'Mikado' ve 'Mogador' çeşitlerinde Bud Feed uygulaması ile meydana gelen 2 günlük erken olgunlaşmanın tam çiçeklenmeden sonraki 30 günde oluşan sıcaklık toplamı (Lopez ve Dejong, 2007) ile tam çiçeklenmeden hasada kadar geçen sıcaklık toplamlarını (Bolat ve íkinci, 2020) daha erken karşılamalarından kaynaklandığı söylenebilir. Nitekim 'Mikado' çeşidinde büyüme derece sıcaklık toplamının Bud Feed uygulamasında tam çiçeklenmeden 30 gün sonra 7.340 saat ve tam çiçeklenmeden hasada kadar geçen sürede 16.109 saat olarak belirlenmiştir. Benzer şekilde 'Mogador' çeşidinde Bud Feed uygulanan bitkilere sıcaklık toplamı değerleri, BDST1 ve BDST2, sırasıyla, 7.801 saat ve 15.153 saat olarak tespit edilmiştir (Çizelge $3)$.

\section{Çiçek açma ve meyve tutum oranları}

Bud Feed uygulamasının 'Mikado' ve 'Mogador' çeşitlerinin çiçek açma ve meyve tutumu özelliklerine etkilerine ait bulgular Çizelge 4'de verilmiştir. İncelenen özelliklere yapılan "T testi" sonuçlarına göre her bir çeşide Bud Feed uygulamasından elde edilen ortalama değerler ile çeşit ortalamaları arasındaki farklar istatistiksel olarak önemli bulunmuştur. 'Mikado' ve 'Mogador' çeşitlerinde Bud Feed uygulamasının çiçek açma oranlarını (sırasıyla, \%97.12 ve \%97.47) kontrole göre (sırasıyla, \%95.16 ve \%91.41) arttırdığı tespit edilmiştir (Çizelge 4). Çeşit ortalamaları karşılaştırıldığında, Mikado çeşidinde çiçek açma oranının (\%96.14) 'Mogador' çeşidine göre (\%94.43) daha yüksek olduğu saptanmıştır. Bu sonuçlara benzer olarak İmrak ve ark (2016), Modi ${ }^{\mathrm{TM}}$ elma çeşidinde \%15 toplam azot içeren uygulamanın kontrolde $\% 50$ olan çiçek tomurcuğu açma oranını \%52.2'ye yükselttiğini bildirmişlerdir.

Mikado çeşidinde ilk meyve tutum oranı ve hasattaki meyve tutum oranı Bud Feed uygulamasında en yüksek (sırasıyla, \%33.75 ve \%9.75) olarak belirlenmiştir. Benzer olarak, 'Mogador' çeşidinde en yüksek ilk meyve tutum oranı ve hasattaki meyve tutma oranı Bud Feed uygulamasında (sırasıyla, \%41.00 ve \%8.63) tespit edilmiştir. Ortalama ilk meyve tutum oranı \%37.25 ile 'Mogador' çeşidinde en yüksek olarak tespit edilirken, hasattaki meyve tutum oranı \%8.38 ile 'Mikado' çeşidinde en yüksek olarak tespit edilmiştir. Her iki çeşidin yetiştirildiği alanda meydana gelen soğuklama 
süresinin çeşitlerin soğuklama gereksinimlerini karşılayacak düzeyde oluştuğu öngörülmekle birlikte, Bud Feed uygulamasının çiçek açma ve meyve tutuma oranlarını arttırdığı tespit edilmiştir. Küden ve Son (1997), 'Precoce de Tyrinthe', 'Tokaloğlu' ve 'Karacabey' çeşitlerinde $\mathrm{KNO}_{3}$ ve thioure uygulamalarının en yüksek tomurcuk patlaması ve meyve tutum oranlarını verdiğini bildirmişlerdir. Kelany ve ark. (2009), 'Canino' kayısı çeşidinde dinlenmenin kesilmesi için hidrojen siyanamid, üre ve mineral yağ uygulamalarının hasattaki meyve tutum miktarını arttırdığını bildirmişlerdir. Benzer sonuçlar, Aksoy ve ark. (1995) ve Mahrous ve El-Fakhrani (2006) tarafından da bildirilmiştir.

\section{Verim özellikleri}

Ağaç başına verim, gövde kesit alanına verim ve dekara verim değerlerinin Bud Feed uygulanan 'Mikado' (sırasıyla, $10.85 \mathrm{~kg}_{\text {ağaç }}{ }^{-1}, 0.39 \mathrm{~kg} \mathrm{~cm}^{-2}$ ve 1.93 ton da ${ }^{-1}$ ) ve 'Mogador' (sırasıyla, $25.29 \mathrm{~kg}_{\text {ağaç }}{ }^{-1}, 0.37 \mathrm{~kg} \mathrm{~cm}^{-2}$ ve 4.22 ton $\mathrm{da}^{-1}$ ) çeşitlerinde en yüksek olduğu saptanmıştır (Çizelge 4). 'Mogador' çeşidinin 'Mikado' çeşidine göre daha yüksek verim özelliklerine (sırasıyla, 17.89 kg ağaç' $1,0.38 \mathrm{~kg} \mathrm{~cm}^{-2}$ ve 3.00 ton $\mathrm{da}^{-1}$ ) sahip olduğu belirlenmiştir. Cook ve ark (2001), 'Peeka' kayısı çeşidinde kontrolde $0.30 \mathrm{~kg} \mathrm{~cm}^{-2}$ olan verimin balon döneminden yaklaşık 6 hafta önce uygulanan hidrojen siyanamid uygulaması ile $0.55 \mathrm{~kg} \mathrm{~cm} \mathrm{~cm}^{-2 \prime}$ nin üzerine çıktığını bildirmişlerdir. Karakum (2016), örtüaltı ve açıkta yetiştirilen 'Precoce de Tyrinthe' kayısı çeşidi ile 'Papaz' ve 'Bekiroğlu' erik çeşitlerinde \%4 hidrojen siyanamid uygulamasının örtüaltındaki verimi arttırdığını belirtmiştir. Demiral ve Ülger (2019), örtüaltında saksıda yetiştirilen 'Aurora', 'Ninfa' ve 'Roxana' kayısı çeşitlerinde dinlenmeyi kesmek amacıyla uygulanan $\% 2.5$ dormeks ve 200 ppm $\mathrm{GA}_{3}$ uygulamlarının kontrol bitkilerine göre önemli miktarda verimde artış sağladığını bildirmişlerdir. Bu sonuçlara benzer olarak, antepfıstığı (Ghrab ve Ben Mimoun, 2014), elma (Nort ve ark., 1990), incir (Theron ve ark., 2011; Gaaliche ve ark., 2017), kiraz (Sheard ve ark., 2009), kivi (Veloso ve ark., 2003) ve şeftali (George ve ark., 1992) gibi meyve türlerinde yapılan çalışmalarda dinlenmeyi kesici uygulamaların meyve verimini arttırdığı ifade edilmiştir.

\section{Meyve kalite özellikleri}

'Mikado' ve 'Mogador' çeşitlerinde Bud Feed uygulamasının meyve kalitesine etkilerine ait sonuçlar Çizelge 5'de sunulmuştur. Meyve kalite değerlerine yapılan "T testi"ne göre her bir çeşide Bud Feed uygulamasının ortalama değerleri ile çeşit ortalamaları arasındaki farklar istatistiksel olarak önemli bulunmuştur. 'Mikado' ve 'Mogador' çeşitlerinde en yüksek meyve ağırlığı değerleri Bud Feed uygulamasından (sırasıyla, $37.43 \mathrm{~g}$ ve $41.72 \mathrm{~g}$ ) elde edilmiştir. 'Mogador' çeşidinin ortalama meyve ağırlığının (39.59 g) 'Mikado' çeşidinden (35.94 g) daha yüksek olduğu saptanmıştır. En yüksek meyve eni, boyu ve yükseklik değerlerine Bud Feed uygulanan 'Mikado' (sırasıyla, $38.40 \mathrm{~mm}, 41.01 \mathrm{~mm}$ ve $41.27 \mathrm{~mm}$ ) ve 'Mogador' (sırasıyla, 38.29 mm, $42.47 \mathrm{~mm}$ ve $41.92 \mathrm{~mm}$ ) çeşitleri sahip olmuştur.

Çizelge 4.'Mikado' ve 'Mogador' çeşitlerinde Bud Feed uygulamasının meyve tutum ve verim özelliklerine etkisi Table 4. Effects of Bud Feed application on fruit set and yield characteristics in 'Mikado' and 'Mogador' cultivars

\begin{tabular}{|c|c|c|c|}
\hline \multirow{2}{*}{ Çeşitler } & \multicolumn{2}{|c|}{ Uygulamalar } & \multirow{2}{*}{ Çeşit Ortalama } \\
\hline & Bud feed & Kontrol & \\
\hline \multicolumn{4}{|c|}{ Çiçek Açma Oranı (\%) } \\
\hline Mikado & $97.12 \mathrm{a}$ & $95.16 \mathrm{~b}$ & $96.14 \mathrm{a}$ \\
\hline Mogador & $97.47 \mathrm{a}$ & $91.41 \mathrm{~b}$ & $94.43 \mathrm{~b}$ \\
\hline \multicolumn{4}{|c|}{ ilk Meyve Tutma Oranı (\%) } \\
\hline Mikado & $33.75 \mathrm{a}$ & $29.50 \mathrm{~b}$ & $31.63 \mathrm{~b}$ \\
\hline Mogador & $41.00 \mathrm{a}$ & $33.50 \mathrm{~b}$ & $37.25 \mathrm{a}$ \\
\hline \multicolumn{4}{|c|}{ Hasattaki Meyve Tutma Oranı (\%) } \\
\hline Mikado & $9.75 \mathrm{a}$ & $7.00 \mathrm{~b}$ & $8.38 \mathrm{a}$ \\
\hline Mogador & $8.63 \mathrm{a}$ & 7.75 b & $8.19 \mathrm{~b}$ \\
\hline \multicolumn{4}{|c|}{ Ağaç Başı Verim (kg ağaç-1) } \\
\hline Mikado & $10.85 \mathrm{a}$ & $11.55 \mathrm{~b}$ & $11.20 \mathrm{~b}$ \\
\hline Mogador & $25.29 \mathrm{a}$ & $10.68 \mathrm{~b}$ & $17.98 \mathrm{a}$ \\
\hline \multicolumn{4}{|c|}{ Gövde Kesit Alanı Verim $\left(\mathrm{kg} \mathrm{cm}^{-2}\right)$} \\
\hline Mikado & $0.39 \mathrm{a}$ & $0.37 \mathrm{~b}$ & $0.38 \mathrm{a}$ \\
\hline Mogador & $0.37 \mathrm{a}$ & $0.32 \mathrm{~b}$ & $0.35 b$ \\
\hline \multicolumn{4}{|c|}{ Dekara Verim (ton da-1) } \\
\hline Mikado & $1.81 \mathrm{~b}$ & $1.93 \mathrm{a}$ & $1.87 \mathrm{~b}$ \\
\hline Mogador & $4.22 \mathrm{a}$ & $1.78 \mathrm{~b}$ & $3.00 \mathrm{a}$ \\
\hline
\end{tabular}


Çeşitlerin meyve boyutları karşılaştırıldığında, Mikado çeşidinin meyve eninin $(37.85 \mathrm{~mm}$ ) 'Mogador' çeşidine (37.65 mm) göre daha yüksek olduğu belirlenirken, 'Mogador' çeşidinin meyve boyu ve yükseklik değerlerinin (sırasıyla, $41.79 \mathrm{~mm}$ ve $41.38 \mathrm{~mm}$ ) 'Mikado' çeşidine göre (sırasıyla, $40.43 \mathrm{~mm}$ ve $41.00 \mathrm{~mm}$ ) daha yüksek olduğu belirlenmiştir. Bu sonuçlara benzer olarak, Son ve Küden (2005), 'Tokaloğlu' ve 'Karacabey' kayısı çeşitlerinde hidrojen siynamid ve promalin uygulamalarının kontrol bitkilerine göre meyve ağırığını \%5 ile \%22 arasında arttırdığını belirtmişlerdir. Ayrıca, Petri ve ark (2010), 'Imperial Gala' ve 'Supremas's Fuji' elma çeşitlerinde uygulanan $\% 15$ azot $+\% 5$ kalsiyum nitrat uygulamasının, uygulama zamanına bağı olarak meyve ağırlığını 'Imperial Gala' da \%4 ile \%26 arasında ve 'Supremas's Fuji' de \%16 ile \%21 arasında bir artış sağladığını ifade etmiştir.

Bud Feed uygulanan 'Mikado' ve 'Mogador' çeşitlerinin kontrole göre meyve eti sertliğinin daha düşük olduğu (sırasıyla, 4.60 ve 2.74 kg-kuvvet) tespit edilmiştir. Çeşitlerin meyve eti sertlikleri karşılaştırıldığında, 'Mikado' çeşidi (4.78 kg-kuvvet) 'Mogador' çeşidine göre (3.70 kg-kuvvet) daha sert meyvelere sahip olmuştur.

Mikado' ve 'Mogador' çeşitlerinde en fazla çekirdek ağırlığı Bud Feed uygulamasında (sırasıyla, 2.78 g ve 2.36 g) saptanmıştır. Ortalama çekirdek ağırlığı $2.63 \mathrm{~g}$ ile 'Mikado' çeşidinde 'Mogador' çeşidine göre (2.32 g) daha fazla olduğu belirlenmiştir. Mikado çeşidinde et/çekirdek değeri en yüksek kontrolde (12.93) tespit edilirken, 'Mogador' çeşidinde en yüksek et/çekirdek değeri Bud Feed uygulamasında (16.69) tespit edilmiştir. Ortalama et/çekirdek değeri bakımından 'Mogador' çeşidi (16.20) Mikado çeşidine göre (12.73) daha yüksek değere sahip olmuştur.

Çizelge 5. 'Mikado' ve 'Mogador' kayısı çeşitlerinde Bud Feed uygulamasının meyve kalite özelliklerine etkisi Table 5. Effect of Bud Feed application on fruit quality characteristics in 'Mikado' and 'Mogador' apricot cultivars

\begin{tabular}{|c|c|c|c|}
\hline \multirow{2}{*}{ Çeşitler } & \multicolumn{2}{|c|}{ Uygulamalar } & \multirow{2}{*}{ Çeşit Ortalama } \\
\hline & Bud feed & Kontrol & \\
\hline \multicolumn{4}{|c|}{ Meyve ağırlığı (g) } \\
\hline Mikado & $37.43 a$ & $34.45 \mathrm{~b}$ & $35.94 \mathrm{a}$ \\
\hline Mogador & $41.72 \mathrm{a}$ & $37.47 \mathrm{~b}$ & $39.59 \mathrm{~b}$ \\
\hline \multicolumn{4}{|c|}{ Meyve Eni } \\
\hline Mikado & $38.40 \mathrm{a}$ & $37.31 \mathrm{~b}$ & $37.85 \mathrm{a}$ \\
\hline Mogador & $38.29 \mathrm{a}$ & $37.01 \mathrm{~b}$ & $37.65 b$ \\
\hline \multicolumn{4}{|c|}{ Meyve boyu (mm) } \\
\hline Mikado & $41.01 \mathrm{a}$ & $39.86 \mathrm{~b}$ & $40.43 b$ \\
\hline Mogador & $42.47 \mathrm{a}$ & $41.11 b$ & $41.79 \mathrm{a}$ \\
\hline \multicolumn{4}{|c|}{ Meyve Yüksekliği (mm) } \\
\hline Mikado & $41.27 \mathrm{a}$ & $40.74 \mathrm{~b}$ & $41.00 \mathrm{~b}$ \\
\hline Mogador & $41.92 \mathrm{a}$ & $40.84 \mathrm{~b}$ & $41.38 \mathrm{a}$ \\
\hline \multicolumn{4}{|c|}{ Meyve Eti Sertliği (kg-kuvvet) } \\
\hline Mikado & $4.60 \mathrm{~b}$ & $4.96 \mathrm{a}$ & $4.78 \mathrm{a}$ \\
\hline Mogador & $2.74 \mathrm{~b}$ & $4.66 \mathrm{a}$ & $3.70 \mathrm{~b}$ \\
\hline \multicolumn{4}{|c|}{ Çekirdek Ağırlığı (g) } \\
\hline Mikado & $2.78 \mathrm{a}$ & $2.48 \mathrm{~b}$ & $2.63 \mathrm{a}$ \\
\hline Mogador & $2.36 \mathrm{a}$ & $2.27 \mathrm{~b}$ & $2.32 \mathrm{~b}$ \\
\hline \multicolumn{4}{|c|}{ Et/çekirdek Oranı (\%) } \\
\hline Mikado & $12.54 \mathrm{~b}$ & $12.93 \mathrm{a}$ & $12.73 \mathrm{~b}$ \\
\hline Mogador & $16.69 \mathrm{a}$ & $15.71 \mathrm{~b}$ & $16.20 \mathrm{a}$ \\
\hline \multicolumn{4}{|c|}{ SÇKM (\%) } \\
\hline Mikado & $9.17 \mathrm{~b}$ & $9.20 \mathrm{a}$ & $9.18 \mathrm{~b}$ \\
\hline Mogador & $12.30 \mathrm{a}$ & $9.77 \mathrm{~b}$ & $11.03 \mathrm{a}$ \\
\hline \multicolumn{4}{|c|}{$\mathrm{pH}$} \\
\hline Mikado & $2.98 \mathrm{~b}$ & $3.04 \mathrm{a}$ & $3.01 \mathrm{~b}$ \\
\hline Mogador & $3.31 \mathrm{a}$ & $3.18 \mathrm{~b}$ & $3.25 \mathrm{a}$ \\
\hline \multicolumn{4}{|c|}{ Titre Edilebilir Asitlik (\%) } \\
\hline Mikado & $2.46 \mathrm{a}$ & $2.34 \mathrm{~b}$ & $2.40 \mathrm{a}$ \\
\hline Mogador & $1.81 \mathrm{~b}$ & $2.06 \mathrm{a}$ & $1.93 \mathrm{~b}$ \\
\hline
\end{tabular}


En yüksek SÇKM içeriği 'Mikado' çeşidinde kontrol uygulamasından (\%9.20) elde edilirken, 'Mogador' çeşidinde en yüksek SÇKM içeriği Bud Feed uygulamasından (\%12.3) elde edilmiştir. 'Mogador' çeşidinin ortalama SÇKM içeriği (\%11.03) 'Mikado' çeşidinden (\%9.18) daha yüksek bulunmuştur. Son ve Küden (2005), kayısı çeşitlerinde dinlemeyi kesici uygulamaların çeşide bağlı olarak meyvelerin SÇKM içeriğini etkilediğini ifade etmişlerdir. Benzer olarak, Demiral ve Ülger (2019), 'Aurora', 'Ninfa' ve 'Roxana' kayısı çeşitlerinde dinlenmeyi kesici uygulamaların çeşitlerde \%1 ile \%7 arasında değişen oranda SÇKM içeriğinde artış sağladığını belirtmişlerdir. Mikado çeşidinde en yüksek $\mathrm{pH}$ değeri kontrol uygulamasında (3.04) tespit edilirken, 'Mogador' çeşidinde en yüksek pH Bud Feed uygulamasında (3.31) tespit edilmiştir. Çeşit ortalamaları karşılaştıııldığında 'Mogador' çeşidinin pH değeri (3.25) Mikado çeşidinden (3.01) daha yüksek bulunmuştur. En yüksek titre edilebilir asitlik oranı Mikado çeşidinde Bud Feed uygulamasından (\%2.46) elde edilirken, 'Mogador' çeşidinde en yüksek titre edilebilir asitlik oranı \%2.06 ile kontrol uygulamasından elde edilmiştir. Çeşit ortalamaları karşılaştırıldığında \%2.40 ile 'Mikado' çeşidinin daha yüksek titre edilebilir asitlik oranına sahip olmuştur. Bu bulgular, kayısıda dinlenmenin kesici uygulamaların çeşitlerin meyve suyu asitlik içeriğini arttırdığına ait Son ve Küden (2005) ve Demiral ve Ülger (2019)'in sonuçlarıyla benzerlik göstermiştir.

Meyve kabuk rengi değerleri incelendiğinde, 'Mikado' çeşidinde rengin parlaklığını gösteren $L$ değerinin kontrolde (64.42) Bud Feed uygulamasına göre (63.73) daha yüksek olduğu tespit edilmiştir (Çizelge 6). 'Mogador' çeşidinde meyve kabuk rengi parlaklığının (L) Bud Feed uygulamasında (61.03) kontrole göre (60.00) daha yüksek olduğu saptanmıştır. Çeşit ortalamaları karşılaştırıldığında, 'Mogador' çeşidi daha parlak meyve kabuk rengine (60.52) sahip olduğu belirlenmiştir. 'Mikado' ve 'Mogador' çeşitlerinde kırmızı (pozitif değer)-yeşil rengi (negatif değer) gösteren a* değeri bakımından, en yüksek değerler Bud Feed uygulamasından (sırasıyla, 11.16 ve 17.49) elde edilmiştir. Ortalama $a^{*}$ değerine göre 'Mogador' çeşidinde (14.60) Mikado çeşidine göre (10.39) daha kırmızı meyveler olduğu saptanmıştır. Sarı rengi ifade eden pozitif $b^{*}$ değeri, Bud Feed uygulanan Mikado ve Mogador çeşitlerinde (sırasıyla, 44.91 ve 45.90) tespit edilmiştir. Ortalama b* değerinin 'Mogador' çeşidinde daha yüksek olduğu (44.96) belirlenmiştir. Rengin yoğunluğunu gösteren $C$ değeri 'Mikado' ve 'Mogador' çeşitlerinde kontrol uygulamasında daha düşük olarak (sırasıyla, 46.07 ve 48.56 ) saptanmıştır. Ortalama C değerinin Mikado çeşidinde daha yoğun olduğu (46.59) belirlenmiştir. Rengin açı değerini ifade eden $h^{\circ}$ değeri, 'Mikado' ve 'Mogador' çeşitlerinde, Bud Feed uygulamasında daha yüksek (75.67 ve 67.65) bulunmuştur.

'Mikado' ve 'Mogador' çeşitlerinde en parlak meyve eti rengini gösteren $L^{*}$ değeri Bud Feed uygulamasında (sırasıyla, 61.16 ve 60.44) belirlenmiştir (Çizelge 6). Meyve etindeki ortalama $L^{*}$ değerinin 'Mikado' çeşidinde (60.41) 'Mogador' çeşidine göre (60.31) daha yüksek olduğu saptanmıştır. Kırmızılığı gösteren pozitif a* değeri 'Mikado' çeşidinde kontrolde (6.97) en yüksek olarak elde edilirken, 'Mogador' çeşidinde en yüksek a* değeri Bud Feed uygulamasından (8.26) elde edilmiştir. Çeşit ortalamalar karşılaştırıldığında 'Mogador' çeşidi daha yüksek meyve eti a* değerini vermiştir. Bud Feed uygulanan 'Mikado' ve 'Mogador' çeşitleri en yüksek meyve eti $b^{*}$ değerine (sırasıyla, 45.45 ve 51.16 ) sahip olmuştur. 'Mogador' çeşidinin meyve eti rengi $b *$ değeri (48.22) Mikado çeşidinden (45.19) yüksek bulunmuştur. 'Mikado' ve 'Mogador' çeşitlerinde meyve eti renk yoğunluğun en fazla kontrol uygulamasında olduğu (sırasıyla, 45.48 ve 45.88 ) tespit edilmiştir. Mikado çeşidi $45.67 \mathrm{C}$ değeri ile daha yoğun meyve et rengine sahip olmuştur. En yüksek $h^{\circ}$ değeri Mikado çeşidinde Bud Feed uygulamasından (82.34) elde edilirken, 'Mogador' çeşidinde en yüksek ho değeri 80.84 ile kontrol uygulamasından elde edilmiştir.

Birçok meyve türünde olduğu gibi kayısıda da meyve kabuk rengi özellikleri meyve olgunluğu ve hasat zamanının belirlenmesinde kullanılmaktadır. Ayrıca, kayısıda meyve rengi tüketici tercihlerini etkileyen önemli özelliklerden biridir. Ruiz ve ark. (2005), kayısılarda yüksek $h^{\circ}$ değerinin daha parlak meyve kabuğu ile ilişkili olduğunu bildirmişlerdir. Bununla birlikte, kayısıda yüksek $C$ değerinin turuncu rengini, düşük $h$ o değerinin meyvenin karatenoid içeriğinin daha yüksek olduğu (Hegedũs ve ark., 2010) ve turuncu renkli çeşitlerin daha zengin fenolik bileşiklere sahip olduğu (Gundogdu ve ark., 2017) belirtilmektedir Bu kapsamda, Mikado ve Mogador çeşitlerinde Bud Feed uygulamasının meyve kabuğunda kırmızı renk oluşumu yanında turuncu renk yoğunluğunu üzerine de olumlu etkileri olduğu tespit edilmiştir.

Sonuç olarak, son yıllarda Akdeniz Bölgesinde kış soğuklarında meydana gelen azalmalar erkenci kayısı çeşitlerinde verim kayıplarına neden olabilmektedir. Erkenci çeşitlerin dinlenmeden çıkarılması yanında verim kaybının önüne geçebilecek pratik uygulamalara da gereksinim duyulmaktadır. Bu kapsamda, erken dönemde olgunlaşan 'Mikado' ve 'Mogador' kayısı çeşitlerinde Bud Feed uygulamasının meyve tutumu, 
verim ve meyve kalitesini arttırdığı belirlenmiştir. Ayrıca, bu uygulanmanın her iki çeşitte de 2 günlük erkencilik sağladığı tespit edilmiştir. Sonuç olarak, Akdeniz Bölgesinde Bud Feed uygulamasının erkenci kayısı çeşitlerinde soğuklama süresinin eksik kalması durumunda oluşabilecek verim kayıplarının önüne geçilmesi için kullanılmasının uygun olduğu söylenebilir.

\section{ÖZET}

Amaç: Bu çalışmada, Bud Feed uygulamasının 'Mikado' ve 'Mogador' kayısı çeşitlerinde meyve tutumu, verim ve meyve kalitesine etkilerinin incelenmesi amaçlanmıştır.

Yöntem ve Bulgular: Çalışmada, Bud Feed uygulaması

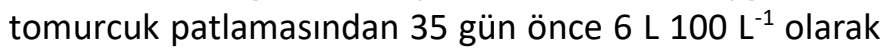
uygulanmıştır. Çalışma sonucunda, Bud Feed uygulamasının kontrole göre ilk meyve tutumunu 'Mikado' çeşidinde \%14.41 ve 'Mogador' çeşidinde \% 22.40 oranında arttırdığı belirlenmiştir. Her iki çeşitte, Bud Feed uygulamasının 2 günlük erkencilik sağladığı tespit edilmiştir. Bu uygulamanın ağaç başına verim ve dekara verim özelliklerini (sırasıyla, $25.29 \mathrm{~kg}_{\text {ağaç }}{ }^{-1}$ ve 4.22 ton $\mathrm{da}^{-1}$ ) 'Mogador' çeşidinde daha fazla arttırdığı saptanmıştır. Ayrıca, 'Mikado' ve 'Mogador' çeşitlerinde Bud Feed uygulamasının meyve iriliğini ve meyve kabuğunda kırmızı yanak oluşumunu arttırdığı belirlenmiştir.

Genel Yorum: Bud Feed uygulamasının soğuklama süresinin yetersiz olduğu sezonlarda kayısılarda uygulanmasının verim ve kalitenin sürekliliği bakımından yararlı sonuçları olduğu belirlenmiştir.

Çalışmanın Önemi ve Etkisi: Akdeniz Bölgesinde kış soğuklarının yeterince oluşmaması erkenci kayısı çeşitlerinde verim kayıplarına neden olabilmektedir. Bu doğrultuda, Bud Feed uygulamasının 'Mikado' ve 'Mogador' çeşitlerinde kullanılabileceği belirlenmiştir.

Anahtar Kelimeler: Kayısı, bud feed, soğuklama süresi, verim, kalite.

\section{TEŞEKKÜR}

Bu çalışmaya katkılarından dolayı Dr. Canan Yılmaz'a (Stoller Türkiye, İzmir) ve İzzet Parlar'a (Parlar Fidancılık, İzmir) çok teşekkür ediyoruz.

\section{ÇIKAR ÇATIŞMA BEYANI}

Yazarlar çalışma konusunda çıkar çatışmasının olmadığını beyan eder.

\section{ARAŞTIRMACILARIN KATKI ORANI BEYANI}

Yazarlar çalışmaya eşit oranda katkı sağlamış olduklarını beyan eder.

\section{KAYNAKLAR}

Aksoy U, Kara S, Misirli A, Can HZ, Seferoglu G (1995) Effect of potassium nitrate and hydrogen cyanamide on apricot. Acta Hort. 384: 431-440.

Anonim (2021a). Türkiye İstatistik Kurumu (TÜiK). https://biruni.tuik.gov.tr/medas/?locale=tr (Erişim Tarihi: 27 Şubat 2021).

Anonim (2021b) Akdeniz ihracatçı Birlikleri (AKiB), Yaş Meyve Sebze Sektörü Türkiye Geneli Değerlendirme Raporu. http://www.yms.org.tr/tr/default.html (Erişim Tarihi: 20 Mart 2021)

Anonim (2021c) Meteoroloji Genel Müdürlüğü (MGM). https://mgm.gov.tr/tarim/bisip.aspx (Erişim Tarihi: 27 Şubat 2021).

Ayanoglu H, Kaska N (1995) Preliminary results of local apricot adaptation studies in the Mediterranean region of Turkey. Acta Hortic. 384: 117-122.

Bolat i, İkinci A (2020) Investigation on heat requirements and fruit growth of some ealry maturing apricot cultivars insemiarid conditions. Frensenius Environmental Bulletin 29: 1542-1549.

Campoy JA, Ruiz D, Cook N, Allderman L, Egea J (2011) Clinal variation of dormancy progression in apricot. South African Journal of Botany 77: 618-630.

Castède S, Campoy JA, García JQ, Le Dantec L, Lafargue M, Barreneche T, Wenden B, Dirlewanger E (2014) Genetic determinism of phenological traits highly affected by climate change in Prunus avium: Flowering date dissected into chilling and heat requirements. New Phytol. 202: 703-715.

Cook NC, Bergh AOD, Strydom DK, Jacobs G (2001) Budburst and yield of 'Peeka' apricot influenced by time and concentration of hydrogen cyanamide application. S. Afr. Plant Soil. 18: 139-141.

Çalışkan O, Bayazıt S, Sümbül A (2012) Fruit quality and phytochemical attributes of some apricot (Prunus armeniaca L.) cultivars as affected by genotypes and seasons. Not. Bot. Horti. Agrobo. 40: 284-294.

Demiral S, Ülger S (2019) Apricot culture in container for earliness. KSÜ J. Agric. Nat. 22: 330-336.

Engin H, Ünal A, Gür E (2004) CCC, PP333, GA3, Dormex ve Ethrel uygulamalarının bazı kiraz çeşitlerinin çiçeklenmesi üzerine etkileri. Ege Üniv. Ziraat Fak. Derg. 41: 35-43. 
Erez A (2000) Bud Dormancy; phenomenon, problems and solutions in the tropics and subtropics, In: Temperate Fruit Crops in Warm Climates (Eds. Erez, A), Springer, Dordrecht. pp. 17-48.

Gaaliche B, Ghrab M, Ben Mimoun M (2017) Effect of hydrogen cyanamide on vegetative growth, yield, and fruit quality of fig $\mathrm{cv}$. Zidi in a warm production area. Int. J. Fruit Sci. 17: 63-71.

George AJ, Lloyd J, Nissen RJ (1992) Effect of pruning date, paclobutrazol and hydrogen cyanimide on dormancy release for low chill Flordaprince peach in subtropical Australia. Aust. J. Ex. Agric. 32:89-98.

Ghrab M, Ben Mimoun M (2014) Effective hydrogen cyanamide (Dormex) application for bud break, flowering and nut yield of pistachio trees cv. Mateur in warm growing areas. Expl. Agric. 50: 398-406.

Gundogdu M, Ercisli S, Berk S, Kan T, Canan I, Gecer MK (2017) Diversity on color and phenolic compounds in apricot fruits. Food Measure 11: 2087-2093.

Hegedũs A, Engel R, Abrankó L, Balogh E, Blázovics A, Hermán $R$, Halász J, Ercisli $S$, Pedryc $A$, Stefanovitsbányai É (2010) Antioxidant and antiradical capacities in apricot (Prunus armeniaca L.) fruits: Variations from genotypes, years, and analytical methods. J. Food Sci. 75: C722-C730.

İmrak B, Küden A, Sarıeroğullarından A, Küden AB (2009) Subtropik koşullarda örtüaltı elma yetiştiriciliği. Tarım Bilim Derg. 2: 187-193.

İmrak B, Küden AB, Küden A, Sarıer AK, Çimen B (2016) Chemical applications affected dormancy breaking in 'Modi' apple cultivar under subtropical conditions. Acta Sci. Pol. Hortorum Cultus 15: 265-277.

Karakum F (2016) Örtüaltında yetiştirilen erik ve kayısı çeşitlerinde hidrojen siyanamid (H2CN2) uygulamasının erkencilik ve verim üzerine etkileri. Yüksek Lisans Tezi, Adnan Menderes Üniversitesi, Fen Bil. Ens., Bahçe Bitkileri ABD, 99s.

Kaşka N, Onur S, Onur C, Çınar A (1981) Akdeniz bölgesi için erkenci kayısı çeşitlerinin seleksiyonu. TÜBiTAKTOAG Sonuç Raporu, 30s, Adana.

Kaşka N (2001) Türkiye'nin sert çekirdekli meyvelerde üretim hedefleri üzerine öneriler. I. Sert Çekirdekli Meyveler Sempozyumu. 25-28 Eylül, Yalova, s.1-16.

Küden AB, Kaşka N (1992) Ilıman iklim meyveleri yetiştiriciliği açısından Adana ve Pozantı'daki soğuklama sürelerinin çeşitli yöntemlerle saptanması. Doğa Tr. J. of Agric. For. 16: 50-62.

Küden $A B$, Son $L$ (1997) Dormancy breaking experiments on apricots. Acta Hortic. 441: 153-158.

Lopez G, DeJong TM (2007) Spring temperatures have a major effect on early stages of peach fruit growth. J. Hortic. Sci. Biotech. 82: 507-512.
Mahrous HAH, El-Fakhrani EMM (2006) Effect of some dormancy breaking agents on productivity, fruit quality and powdery mildew severity of apricot. Acta Hortic. 701: 659-664.

Melgarejo P, Calin-Sanchez A, Carbonell-Barrachina A, Martinez-Nicolas JJ, Legua $P$, Martinez R, Hernandez F (2013) Antioxidant activity, volatile compositionand sensory profile of four new very-early apricots (Prunus armeniaca L). J. Sci. Food Agric. 94: 85-94.

Melgarejo $P$, Legua $P$, martinez-Font $R$, Martinez-Nicolas JJ, Sorianop JS, Calin-Sanchez A, Carbonell-Barrachina A, Hernandez F (2021) Response of apricot fruit quality to protective netting. Agriculture 11, 260. https://doi.org/10.3390/agriculture11030260.

North M, Cutting JGM, Jacobs G (1990) Effects of the rest breaking agent cynamide on cytokinin levels in apple shoots and buds. XXIII International Congress, Firenze, Italy), August 27-September1, pp 4216.

Petri JL, Leite GB, Hawerroth FJ (2010) Time of Erger application for budbreak induction in apple trees. Acta Hortic. 872: 205-210.

Richardson EA, Seeley SD, Walker DR, Anderson JL, Ashcroft GL (1975) Pheno-climatography of spring peach bud develoment. HortScience 10: 236-237.

Ruiz D, Egea J, Tomas-Barberan FA, Gil M (2005). Carotenoids from new apricot (Prunus armeniaca L.) varieties and their relationship with flesh and peel color. J. Agric. Food Chem. 53: 6368-6374.

Sas , 2005. SAS online doc, version 9.1.3. SAS Inst., Cary, NC, USA.

Sheard AG, Johnson SD, Cook NC (2009) Effect of timing and concentration of rest breaking agents on budburst in 'Bing' sweet cherry under conditions of inadequate winter chilling in South Africa. S. Afr. J. Plant Soil 26: 73-79.

Son L, Küden AB (2005) Dormex and promalin affects fruit set and earliness of apricot (Prunus armeniaca) and plum (Prunus domestica) cultivars. N Z J Crop Hortic. Sci. 33: 59-64.

Theron KI, Gerber HJ, Steyn WJ (2011) Effect of hydrogen cyanamide, mineral oil and thidiazuron in combination with tip pruning on bud break, shoot growth and yield in 'Bourjasotte Noire', 'Col de Damme Noire' and 'Noire de Caromb' figs. Sci. Hortic. 128: 239-248.

Veloso A, Oliveira M, Antunes MDC (2003) The effect of hydrogen cyanamide on bud break and yield of kiwifruit in Northwest Portugal. Acta Hortic. 610: 161164. 
Viti R, Bartolini S, Andreini L (2008) Apricot flower bud development: Main biological, physiological and environmental aspects related to the appearance of anomalies. Int. J. Plant Dev. Biol. 2: 25-34.

Weinberger JH (1950) Chilling requirements of peach varieties. Am. Soc. Hortic. Sci. 56: 122-128.

Westwood MN (1995) Temperate Zone Pomology. Timber Pres, Oregon, pp.523.

Yelmen H (2007) Doğu Akdeniz Bölgesinde farklı soğuklama yöntemleri kullanılarak olasılıklı soğuklama süre haritasının çıkarılması. Yüksek Lisans Tezi, Çukurova Üniversitesi, Fen Bilim. Enst., Bahçe Bitkileri ABD, 132s.
Zhuang W, Gao Z, Wen L, Huo X, Cai B, Zhang Z (2015) Metabolic changes upon flower bud break in Japanese apricot are enhanced by exogenous GA4. Hortic Res 2: 15046, doi:10.1038/hortres.2015.46. 